\title{
Title: The geographical distribution of fossil fuels unused when limiting global warming to $2^{\circ} \mathrm{C}$
}

\author{
Authors: Christophe McGlade ${ }^{\dagger}$, Paul Ekins ${ }^{\dagger}$
}

\begin{abstract}
Affiliation
${ }^{\dagger}$ University College London (UCL) Institute for Sustainable Resources, Central House, 14 Upper Woburn Place London WC1H 0NN
\end{abstract}

Summary

Policy makers have agreed that the average global temperature rise caused by greenhouse gas emissions should not exceed 2 \{degree sign\}C above pre-industrial times ${ }^{1}$. It has been estimated that to have at least a 50 per cent chance of keeping warming below 2 \{degree sign\}C throughout the twenty-first century, the cumulative carbon emissions between 2011 and 2050 needs to be limited to around 1,100 Gt $\mathrm{CO}_{2}^{2,3}$. However, the greenhouse gas emissions contained in current estimates of global fossil fuel reserves are around three times higher than this ${ }^{2,4}$, and so the unabated use of all current fossil fuel reserves is incompatible with a 2 \{degree sign\}C warming limit. Here we use a single integrated assessment model that contains estimates of the quantities, locations and nature of the world's oil, gas and coal reserves and resources, and which is shown to be consistent with a wide variety of modelling approaches with differing assumptions ${ }^{5}$, to explore the implications of this emissions limit for different regions' fossil fuel production. Our results suggest that, globally, a third of oil reserves, half of gas reserves and over 80 per cent of current coal reserves should remain unused from $2010-2050$ in order to meet the $2^{\circ} \mathrm{C}$ 
target. We show that development of resources in the Arctic and any increase in unconventional oil production are incommensurate with efforts to limit climate change. Our results show that policy makers' instincts to exploit rapidly and completely their territorial fossil fuels are, in aggregate, inconsistent with their commitments to the $2^{\circ} \mathrm{C}$ temperature limit. Implementation of this policy commitment would also call into question the need for companies' substantial fossil fuel exploration budgets as the new discoveries could not lead to increased aggregate production.

Recent climate studies have demonstrated that average global temperature rises are closely related to cumulative emissions of greenhouse gases emitted over a given timeframe ${ }^{2,6,7}$. This has resulted in the concept of the remaining global 'carbon budget' associated with the probability of successfully keeping the temperature rise below a certain level ${ }^{4,8,9}$, with the IPCC ${ }^{3}$ recently suggesting that to have a better-than-evens chance of avoiding more than a $2^{\circ} \mathrm{C}$ temperature rise, the carbon budget between 2011 and 2050 is around $870-1,240 \mathrm{Gt}^{\mathrm{CO}_{2}}$.

Such a carbon budget will have profound implications for the future utilisation of oil, gas and coal. However to understand the quantities that are required, and are not required, under different scenarios, we first need to establish the quantities and location of those currently estimated to exist. A variety of metrics with disparate nomenclature are relied upon to report the availability of fossil fuels ${ }^{10,11}$, but the two most common are 'resources' and 'reserves'. In this work 'resources' are taken to be the remaining ultimately recoverable resources (RURR) - the quantity of oil, gas or coal remaining that is recoverable over all time with both current and future technology, irrespective of current economic conditions. 'Reserves' (Res) are a subset of resources that are defined to be: recoverable under current economic conditions and have a 
specific probability of being produced ${ }^{11}$. Our best estimates of the reserves and resources are presented in Fig. 1 and, at the regional level, in Extended Data Table 1.

Fig. 1 also compares the above carbon budget with the $\mathrm{CO}_{2}$ emissions that would result from the combustion of our estimate of remaining fossil fuel resources (nearly $11,000 \mathrm{Gt} \mathrm{CO}_{2}$ ). With combustion emissions of remaining reserves alone totalling nearly $2,900 \mathrm{Gt} \mathrm{CO}_{2}$, the disparity between what resources and reserves exist and what can be emitted while avoiding a temperature rise greater than the agreed $2^{\circ} \mathrm{C}$ limit is therefore stark.

While previous research ${ }^{12}$ has examined the implications that emissions mitigation might have on the rents collected by fossil fuel resource owners, more pertinent to policy and industry are the quantities of fossil fuel that are not used prior to 2050 in scenarios that limit the average global surface temperature rise to $2^{\circ} \mathrm{C}$. Such geographically-disaggregated estimates of 'unburnable' reserves and resources are provided here using the linear optimisation, integrated assessment model TIAM-UCL ${ }^{13}$.

To provide context to the issue of unburnable fossil fuels and our results, it is useful to examine scenarios provided by other models that quantify separately the volumes of oil, gas and coal produced globally under a range of future emissions trajectories ${ }^{5}$. The ranges of cumulative production between 2010 and 2050 from these are presented in Fig. 2. Since they have very different future GHG emissions profiles, we have converted them to approximate temperature rise trajectories. These have been calculated using the climate model MAGICC ${ }^{14}$, which generates a probability distribution over temperature rise trajectories for a given emissions profile. We use the $60^{\text {th }}$ percentile temperature trajectory (to correspond with assumptions within TIAM-UCL) and then group the scenarios by the final temperature rise in 2100, either: a) below 
$2^{\circ} \mathrm{C}$, b) between $2^{\circ} \mathrm{C}$ and $3^{\circ} \mathrm{C}$, or c) exceeding $3^{\circ} \mathrm{C}$.

In this work we have constructed three core scenarios that are constrained to limit the average surface temperature rise in all time periods to $2^{\circ} \mathrm{C}$, to $3^{\circ} \mathrm{C}$, and to $5^{\circ} \mathrm{C}$. Cumulative production of each fossil fuel between 2010 and 2050 in each of these scenarios can be identified within each of the three temperature groupings in Fig. 2.

The global reserves of oil, gas and coal included in Fig. 1 total approximately 7,400 EJ, 7,100 EJ, and 20,000 EJ respectively. With narrow inter-quartile ranges, relative to the level of reserves available, Fig 2 shows good agreement on the levels of fossil fuels produced within the groups, despite the range of modelling methodologies and assumptions included.

Since assumptions in modelling the energy system are subject to wide bands of uncertainty $y^{15}$, we further constructed a number of sensitivity scenarios using TIAM-UCL that remain within a $2^{\circ} \mathrm{C}$ temperature rise. These span a broad range of assumptions on production costs, bio-energy, oil, and gas availability, demand projections, and technology availability (one with no negative emissions technologies, and one with no carbon capture and storage (CCS)) (Extended Data Table 2). The availability of CCS has the largest effect on cumulative production levels (Extended Data Fig. 1); however, there is little variability in the total production of fossil fuels if the world is to have a good chance of staying within the agreed $2^{\circ} \mathrm{C}$ limit.

Global production of oil, gas and coal over time in our main $2^{\circ} \mathrm{C}$ scenario is given in Fig. 3 . This separates production by 'category', i.e. the individual kinds of oil and gas that make up the global resource base, and compares total production with the projections from the $2^{\circ} \mathrm{C}$ scenarios in Fig. 2. The results generated using TIAM-UCL are a product of the economically-optimal solution, and other regional distributions of unburnable reserves are possible while still remaining within 
the $2^{\circ} \mathrm{C}$ limit (even though these would have a lower social welfare). While a future multi-model analysis could therefore usefully build on and extend the work that is presented here, results at the aggregate level can be seen to lie in range of the ensemble of models and scenarios that also give no more than a $2^{\circ} \mathrm{C}$ temperature rise.

In the TIAM-UCL scenarios, production of reserves and non-reserve resources occurs contemporaneously. It is therefore important to recognise that it would be inappropriate simply to compare the cumulative production figures in Fig. 2 with the reserve estimates from Fig. 1 and declare any reserves not used as 'unburnable'. While there may be sufficient reserves to cover cumulative production between 2010 and 2050, it does not follow that only reserves need to be developed and all other resources remain unused. For oil and gas, resources that are not currently reserves may turn out to be cheaper to produce than some reserves, while new resources will also be developed to maintain the flow rates demanded by end-use sectors. However, if resources that are currently non-reserves are produced, a greater proportion of reserves must not be produced to stay within the carbon budget.

The reserves of oil, gas and coal that should be classified as unburnable within each region, and the percentage of current reserves that remain unused, are set out in Table 1. Since total production is most sensitive to assumptions on CCS, and since it has been suggested that the deployment of CCS will permit wider exploitation of fossil fuel resource base ${ }^{16}$, Table 1 includes the unburnable reserves from two alternative $2^{\circ} \mathrm{C}$ scenarios. One scenario permits the widespread deployment of CCS from 2025 onwards, and the other assumes that CCS is unavailable in any time period.

Globally, when CCS is permitted, over 430 billion barrels (Gb) of oil and 95 trillion 
cubic meters $(\mathrm{Tcm})$ of gas currently classified as reserves should remain unburned by 2050 . The Middle East, although using over $60 \%$ of its oil reserves, carries over half of the unburnable oil globally, leaving over $260 \mathrm{~Gb}$ in the ground. Canada has the lowest utilisation of its oil reserves (25\%), as its unconventional oil deposits remain largely undeveloped - this is examined in more detail below - while the United States has the highest, given the proximity of supply and demand centres. The Middle East also holds half of unburnable global gas reserves, with Former Soviet Union countries accounting for another third, meaning that they can use only half their current reserves.

Coal reserves are by far the least used fossil fuel, with a global total of $82 \%$ remaining unburned prior to 2050. The United States and the Former Soviet Union countries each use less than $10 \%$ of their current reserves, meaning that they should leave over 200 billion tonnes (Gt) coal (both hard and lignite) reserves unburned. Coal reserve utilisation is twenty five percentage points higher in China and India, but still they should also leave nearly $200 \mathrm{Gt}$ of their current coal reserves unburned.

The utilisation of current reserves is lower in nearly all regions for all of the fossil fuels when CCS is not available, although there is a slight increase in gas production in some regions to offset some of the larger drop in coal production. Nevertheless, Table 1 demonstrates that the reserves of coal that can be burned are only six percentage points higher when CCS is allowed, with the utilisation of gas and oil increasing by an even smaller fraction (around two percentage points). Because of its expense, its relatively late date of introduction (2025), and the maximum build rates that are assumed, CCS has a relatively modest effect on the overall levels of fossil fuel that can be produced before 2050 in a $2^{\circ} \mathrm{C}$ scenario. 
As shown in Fig. 3, there is substantial production of many of the non-reserve resource categories of oil and gas. Extended Data Table 3 sets out the regional unburnable resources of all coal, gas and oil in the scenario that allows CCS by comparing cumulative production of all fossil fuel resources with the resource estimates in Fig. 1.

The RURR of both types of coal and unconventional oil vastly exceed cumulative production between 2010 and 2050, with the overwhelming majority remaining unburned. Resources of conventional oil are utilised to the greatest extent, with just under $350 \mathrm{~Gb}$ of nonreserve resources produced over the model timeframe. The Middle East again holds the largest share of the unburnable resources of conventional oil, but there is a much wider geographical distribution of these unburnable resources than was the case for oil reserves.

Regarding the production of unconventional oil, open-pit mining of natural bitumen ${ }^{17}$ in Canada soon drops to negligible levels after 2020 in all scenarios as it is considerably less economic than other methods of production. Production by in situ technologies continues in the $2^{\circ} \mathrm{C}$ scenario that allows CCS, but this is accompanied by a rapid and total decarbonisation of the auxiliary energy inputs required (Extended Data Fig. 2). Although such a decarbonisation would be extremely challenging in reality, cumulative production of Canadian bitumen between 2010 and 2050 is still only $7.5 \mathrm{~Gb} .85 \%$ of its $48 \mathrm{~Gb}$ bitumen reserves thus remain unburnable if the $2^{\circ} \mathrm{C}$ limit is not to be exceeded. When CCS is not available, all bitumen production ceases by 2040. In both cases, the RURR of Canadian bitumen dwarfs cumulative production, so that around $99 \%$ of our estimate of its resources $(640 \mathrm{~Gb})$, remains unburnable.

Similar results are seen for extra-heavy oil in Venezuela. Cumulative production is $3 \mathrm{~Gb}$, meaning that almost $95 \%$ of its extra-heavy reserves and $99 \%$ of the RURR are unburnable, even 
when CCS is available.

The utilisation of unconventional gas resources is considerably higher than unconventional oil. Under the $2^{\circ} \mathrm{C}$ scenario, gas plays an important role in displacing coal from the electrical and industrial sectors and so there is over $50 \mathrm{Tcm}$ unconventional gas production globally, over half of which occurs in North America. Nevertheless, there is a low level of utilisation of the large potential unconventional gas resources held by China and India, Africa and the Middle East, and so over $80 \%$ of unconventional gas resources $(247 \mathrm{Tcm})$ are unburnable prior to 2050. Production of these unconventional gas resources is, however, only possible if the levels of coal reserves identified in Table 1 are not developed i.e. it is not possible for unconventional gas to be additional to current levels of coal production.

Finally, we estimate there to be $100 \mathrm{~Gb}$ oil (including NGL) and $35 \mathrm{Tcm}$ gas in fields within the Arctic Circle that are not being produced as of 2010. However, none is produced in any region in either of the $2^{\circ} \mathrm{C}$ scenarios prior to 2050. These results indicate to us that all Arctic resources should be classified as unburnable.

To conclude, these results demonstrate that a stark transformation in our understanding of fossil fuel availability is necessary. While there have previously been fears over the scarcity of fossil fuels ${ }^{18}$, in a climate-constrained world this is no longer a relevant concern: large portions of the reserve base and an even greater proportion of the resource base should not be produced if the temperature rise is to remain below $2^{\circ} \mathrm{C}$.

\section{References:}

1. UNFCCC. Report of the Conference of the Parties on its fifteenth session, held in Copenhagen from 7 to 19 December 2009. Part Two: Action taken by the Conference of the 
Parties at its fifteenth session. 2009 United Nations Clim. Chang. Conf. 43 (UNFCC, 2009).

2. Meinshausen, M. et al. Greenhouse gas emission targets for limiting global warming to $2^{\circ} \mathrm{C}$. Nature 458, 1158-1162 (2009).

3. Clarke, L. et al. in Clim. Chang. 2014 Mitig. Clim. Chang. (Edenhofer, O. et al.) Ch. 6 (Cambridge University Press, 2014).

4. Raupach, M. R. et al. Sharing a quota on cumulative carbon emissions. Nat. Clim. Chang. 4, 873-879 (2014).

5. IPCC WGIII. IAMC AR5 Scenario Database. (2014). at <https://secure.iiasa.ac.at/webapps/ene/AR5DB/>

6. Allen, M. R. et al. Warming caused by cumulative carbon emissions towards the trillionth tonne. Nature 458, 1163-1166 (2009).

7. Matthews, H. D., Gillett, N. P., Stott, P. A. \& Zickfeld, K. The proportionality of global warming to cumulative carbon emissions. Nature 459, 829-832 (2009).

8. Friedlingstein, P. et al. Persistent growth of $\mathrm{CO} 2$ emissions and implications for reaching climate targets. Nat. Geosci 7, 709-715 (2014).

9. Leaton, J. Unburnable carbon - are the world's financial markets carrying a carbon bubble? (Investor Watch, 2011). at <http://www.carbontracker.org/wpcontent/uploads/downloads/2012/08/Unburnable-Carbon-Full1.pdf >

10. McGlade, C. E. A review of the uncertainties in estimates of global oil resources. Energy 47, 262-270 (2012).

11. SPE, AAPG, WPC \& SPEE. Petroleum resources management system. (2008). at <www.spe.org/industry/docs/Petroleum_Resources_Management_System_2007.pdf>

12. Bauer, N. et al. Global fossil energy markets and climate change mitigation - an analysis with REMIND. Clim. Change 1-14 (2013). doi:10.1007/s10584-013-0901-6

13. Anandarajah, G., Pye, S., Usher, W., Kesicki, F. \& McGlade, C. E. TIAM-UCL Global 
Model Documentation. (2011).

14. Meinshausen, M., Raper, S. C. B. \& Wigley, T. M. L. Emulating atmosphere-ocean and carbon cycle models with a simpler model, MAGICC6 - Part 1: Model description and calibration. Atmos. Chem. Phys. 11, 1417-1456 (2011).

15. Usher, W. \& Strachan, N. Critical mid-term uncertainties in long-term decarbonisation pathways. Energy Policy 41, 433-444 (2012).

16. IEA. Resources to Reserves. (International Energy Agency, 2013).

17. AER. Alberta's Energy Reserves 2013 and Supply/Demand Outlook 2014-2023. (2014).

18. Yergin, D. The prize: the epic quest for oil, money \& power. (SimonandSchuster. com, 2009).

19. McKelvey, V. E. Mineral resource estimates and public policy. Am. Sci. 60, 32-40 (1972).

20. McGlade, C. E., Speirs, J. \& Sorrell, S. Unconventional gas - a review of regional and global resource estimates,. Energy 55, 571-584 (2013).

21. Federal Institute for Geosciences and Natural Resources (BGR). Energy Study 2012. Reserves, Resources and Availability of Energy Resources. (2012).

22. McGlade, C. E. Uncertainties in the outlook for oil and gas. (2013).

23. Klett, T. \& Schmoker, J. in Giant oil gas fields Decad. 1990-1999 (Halbouty, M. T.) 107 122 (The American Association of Petroleum Geologists, 2003).

24. Attanasi, E. D. \& Freeman, P. A. Survey of Stranded Gas and Delivered Costs to Europe of Selected Gas Resources. SPE Econ. Manag. 3, 149-162 (2011).

25. IEA. World Energy Outlook. 659 (International Energy Agency, 2008).

26. Trinnaman, J. \& Clarke, A. Survey of Energy Resources. (World Energy Council, 2010). at <http://www.worldenergy.org/publications/3040.asp>

27. IEA. World Energy Outlook. (2013). 
28. IEA. World Energy Outlook. 659 (International Energy Agency, 2011).

29. Rogner, H.-H. et al. in Glob. Energy Assess. - Towar. a Sustain. Futur. 423-512 (2012). at <www.globalenergyassessment.org>

30. Owen, N. A., Inderwildi, O. R. \& King, D. A. The status of conventional world oil reserves - Hype or cause for concern? Energy Policy 38, 4743-4749 (2010).

31. McGlade, C. \& Ekins, P. Un-burnable oil: An examination of oil resource utilisation in a decarbonised energy system. Energy Policy 64, 102-112 (2014).

32. IEA. World Energy Outlook. 691 (International Energy Agency, 2009).

33. Committee on Climate Change. Bioenergy review: Technical Paper 2 - Global and UK bioenergy supply scenarios. (2011).

34. O'Neill, B. C. et al. A new scenario framework for climate change research: the concept of shared socioeconomic pathways. Clim. Change 122, 387-400 (2014).

35. Campbell, C. J. Atlas of Oil and Gas Depletion. 456 (Springer, 2013).

36. Herrmann, L. et al. Oil and Gas for Beginners. (Deutsche Bank, 2013).

37. Klett, T. R. et al. An assessment of potential additions to conventional oil and gas resources of the world (outside the United States) from reserve growth. (2012). at <http://pubs.usgs.gov/fs/2012/3052/fs2012-3052.pdf>

38. Klett, T. R. et al. Potential additions to conventional oil and gas resources in discovered fields of the United States from reserve growth, 2012. (2012).

39. Ahlbrandt, T., Charpentier, R., Klett, T., Schmoker, J. \& Schenk, C. USGS World Petroleum Assessment 2000. (US Dept. of the Interior, US Geological Survey, 2000).

40. Bentley, R., Miller, R., Wheeler, S. \& Boyle, G. UKERC Review of Evidence on Global Oil Depletion: Annex 1 - Models of global oil supply for the period 2008-2030. (2009).

41. Brownfield, M., Charpentier, R. R., Cook, T., Gautier, D. L. \& Higley, D. K. An estimate 
of undiscovered conventional oil and gas resources of the world, 2012. (2012). at <http://pubs.usgs.gov/fs/2012/3042/fs2012-3042.pdf>

42. Gautier, D. L. et al. Assessment of Undiscovered Oil and Gas in the Arctic. Science (80-. ). 324, 1175-1179 (2009).

43. Smith, T. Arctic Dreams - a reality check. Geo ExPro 16-24 (2007).

44. Shah, A. et al. A review of novel techniques for heavy oil and bitumen extraction and upgrading. Energy Environ. Sci. 3, 700 (2010).

45. Clarke, B. NPC Global Oil and Gas Study: Topic Paper 22 - Heavy oil. (National Petroleum Council, 2007).

46. Schenk, C. et al. An estimate of recoverable heavy oil resources of the Orinoco oil belt, Venezuela. (2009).

47. Attanasi, E. D. \& Meyer, R. F. in 2010 Surv. Energy Resour. 123-150 (World Energy Council, 2010).

48. Johnson, R. C., Mercier, T. J. \& Brownfield, M. Assessment of in-place oil shale resources of the Green River Formation, Greater Green River Basin in Wyoming, Colorado, and Utah. (USGS, 2011). at <http://pubs.usgs.gov/fs/2011/3063/pdf/FS11-3063.pdf>

49. Dyni, J. Geology and resources of some world oil-shale deposits. (U.S. Geological Survey, 2006).

50. Biglarbigi, K., Mohan, H. \& Carolus, M. Potential for oil shale development in the United States. (2009). at <http://www.inteki.com/reports.html>

51. Cedigaz. Natural Gas in the World, end of July 2008. (Centre International d'Information sur le Gaz Naturel et tous Hydrocarbures Gazeux (CEDIGAZ), 2009).

52. ERCB. Alberta's Energy Reserves 2011 and Supply/Demand Outlook 2012-2021. 290 (Energy Resources Conservation Board, 2012). 


\section{End notes:}

\section{Acknowledgments}

The authors thank Ilkka Keppo at the UCL Energy Institute, Evelina Trutnevyte at ETH Zurich, and Anne-Marie Lyne at the UCL Department of Statistical Science. This research formed part of the programme of the UK Energy Research Centre and was supported by the UK Research Councils under Natural Environment Research Council award NE/G007748/1.

\section{Author Information}

Reprints and permissions information is available at www.nature.com/reprints

\section{Author Contributions}

The two authors contributed equally to this work.s

\section{Corresponding author}

Correspondence and requests for materials should be addressed to christophe.mcglade@ucl.ac.uk

\section{Competing financial interests}

The authors declare no competing financial interests. 


\begin{tabular}{|c|c|c|c|c|c|c|c|c|c|c|c|c|}
\hline \multirow[b]{3}{*}{ Country or region } & \multicolumn{6}{|c|}{$2^{\circ} \mathrm{C}$ with CCS } & \multicolumn{6}{|c|}{$2^{\circ} \mathrm{C}$ without CCS } \\
\hline & \multicolumn{2}{|c|}{ Oil } & \multicolumn{2}{|c|}{ Gas } & \multicolumn{2}{|c|}{ Coal } & \multicolumn{2}{|c|}{ Oil } & \multicolumn{2}{|c|}{ Gas } & \multicolumn{2}{|c|}{ Coal } \\
\hline & $\mathrm{Gb}$ & $\%$ & Tcm & $\%$ & Gt & $\%$ & $\mathrm{~Gb}$ & $\%$ & $\mathrm{Tcm}$ & $\%$ & Gt & $\%$ \\
\hline Africa & 23 & $21 \%$ & 4.4 & $33 \%$ & 28 & $85 \%$ & 28 & $26 \%$ & 4.4 & $34 \%$ & 30 & $90 \%$ \\
\hline Canada & 39 & $74 \%$ & 0.3 & $24 \%$ & 5.0 & $75 \%$ & 40 & $75 \%$ & 0.3 & $24 \%$ & 5.4 & $82 \%$ \\
\hline China and India & 9 & $25 \%$ & 2.9 & $63 \%$ & 180 & $66 \%$ & 9 & $25 \%$ & 2.5 & $53 \%$ & 207 & $77 \%$ \\
\hline FSU & 27 & $18 \%$ & 31 & $50 \%$ & 203 & $94 \%$ & 28 & $19 \%$ & 36 & $59 \%$ & 209 & $97 \%$ \\
\hline CSA & 58 & $39 \%$ & 4.8 & $53 \%$ & 8 & $51 \%$ & 63 & $42 \%$ & 5.0 & $56 \%$ & 11 & $73 \%$ \\
\hline Europe & 5.0 & $20 \%$ & 0.6 & $11 \%$ & 65 & $78 \%$ & 5.3 & $21 \%$ & 0.3 & $6 \%$ & 74 & $89 \%$ \\
\hline Middle East & 263 & $38 \%$ & 46 & $61 \%$ & 3.4 & $99 \%$ & 264 & $38 \%$ & 47 & $61 \%$ & 3.4 & $99 \%$ \\
\hline OECD Pacific & 2.1 & $37 \%$ & 2.2 & $56 \%$ & 83 & $93 \%$ & 2.7 & $46 \%$ & 2.0 & $51 \%$ & 85 & $95 \%$ \\
\hline ODA & 2.0 & $9 \%$ & 2.2 & $24 \%$ & 10 & $34 \%$ & 2.8 & $12 \%$ & 2.1 & $22 \%$ & 17 & $60 \%$ \\
\hline United States & 2.8 & $6 \%$ & 0.3 & $4 \%$ & 235 & $92 \%$ & 4.6 & $9 \%$ & 0.5 & $6 \%$ & 245 & $95 \%$ \\
\hline Global & 431 & $33 \%$ & 95 & $49 \%$ & 819 & $82 \%$ & 449 & $35 \%$ & 100 & $52 \%$ & 887 & $88 \%$ \\
\hline
\end{tabular}

Table 1: Regional distribution of reserves unburnable before 2050 in absolute terms and as a percentage of current reserves under the $2^{\circ} \mathrm{C}$ scenarios that allow and do not allow CCS. FSU is the Former Soviet Union countries, CSA Central and South America, and ODA Other Developing Asia. 


\section{Figure Legends}

Figure 1: Supply cost curves for oil (a), gas (b) and coal (c) and the combustion $\mathrm{CO}_{2}$ emissions for these resources (d). Globally there are 1,294 billion barrels (Gb) oil, 192 trillion cubic metres (tcm) gas, 728 billion tonnes (Gt) hard coal, and $276 \mathrm{Gt}$ lignite classified as reserves, which would result in 2,900 Gt $\mathrm{CO}_{2}$ if combusted unabated. The range of carbon budgets between 2011 and 2050 approximately commensurate with limiting the temperature rise to $2^{\circ} \mathrm{C}\left(870-1,240 \mathrm{Gt} \mathrm{CO}_{2}\right)$ is also shown.

Figure 2: Cumulative production between 2010-2050 from a range of long-term energy system scenarios ${ }^{5}$ of coal and gas (a), coal and oil (b), and gas and oil (c). Scenarios are coloured according to their approximate resultant 2100 temperature rise above pre-industrial levels. 379 individual scenarios result in a temperature rise below $2^{\circ} \mathrm{C}$ (green), 366 are between $2^{\circ} \mathrm{C}$ and $3{ }^{\circ} \mathrm{C}$ (orange), and 284 exceed $3^{\circ} \mathrm{C}$ (red). Triangles are the values from the $2^{\circ} \mathrm{C}$ (with CCS), $3^{\circ} \mathrm{C}$ and $5^{\circ} \mathrm{C}$ TIAM-UCL scenarios.

Figure 3: Oil, gas and coal production in the TIAM-UCL $2^{\circ} \mathrm{C}$ scenario (with CCS) and comparison with all other $2^{\circ} \mathrm{C}$ scenarios in the IPCC AR5 database ${ }^{5}$. (a), (c) and (e) compare total production by oil, gas and coal with the AR5 database, (b), (d) and (f) provide a disaggregated view of production from the TIAM-UCL scenario separated by category. 

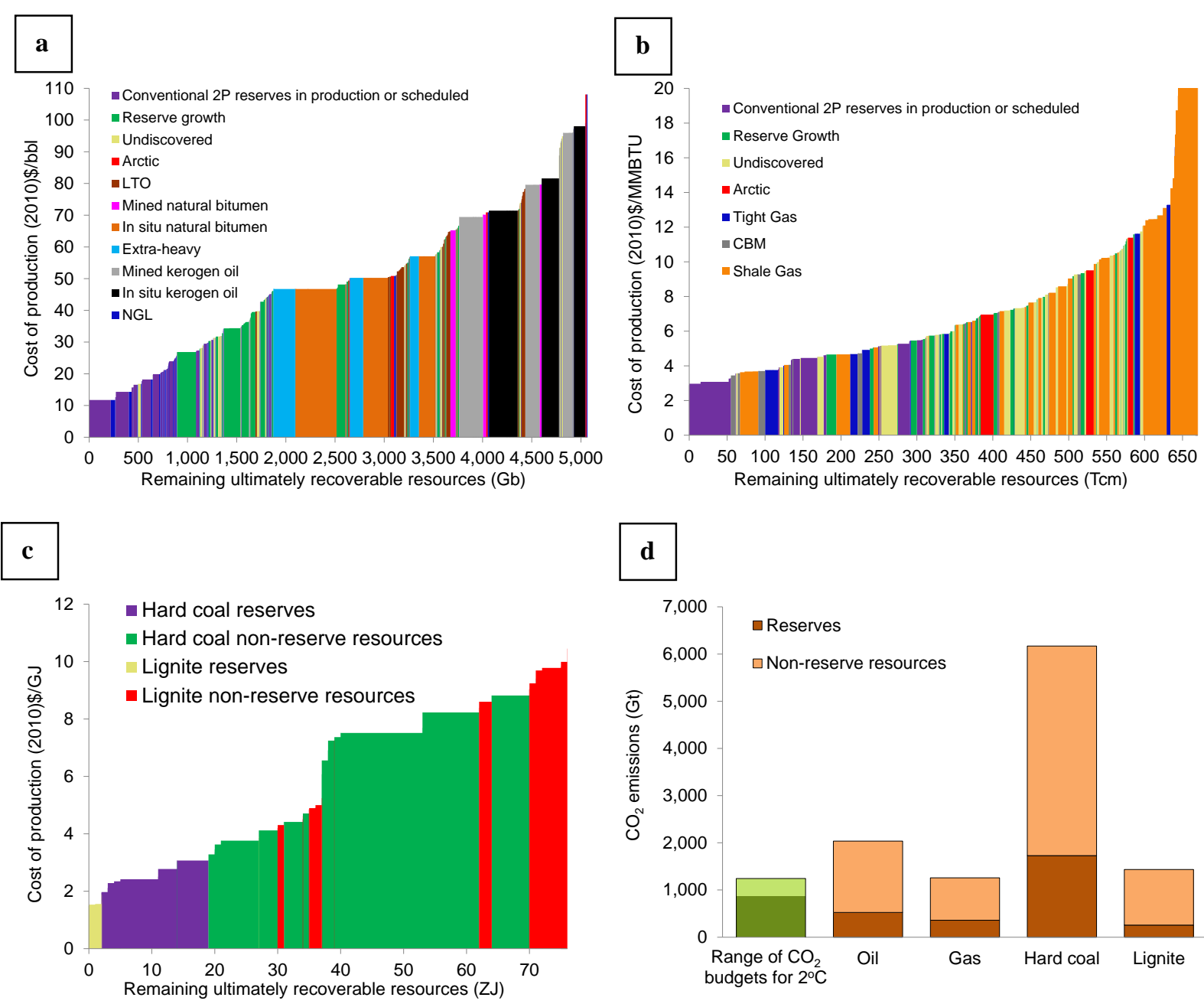

Figure 1: Supply cost curves for oil (a), gas (b) and coal (c) and the combustion $\mathrm{CO}_{2}$ emissions for these resources (d). 


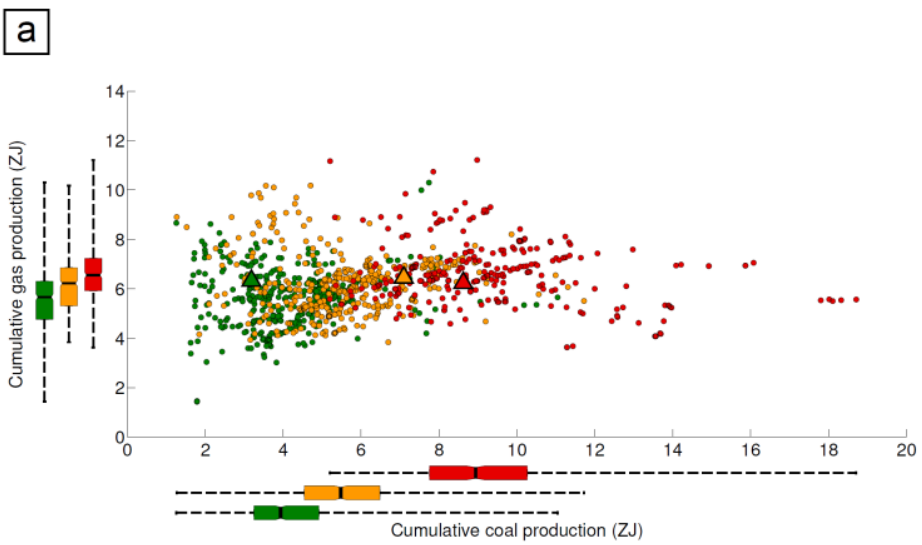

$\mathrm{b}$

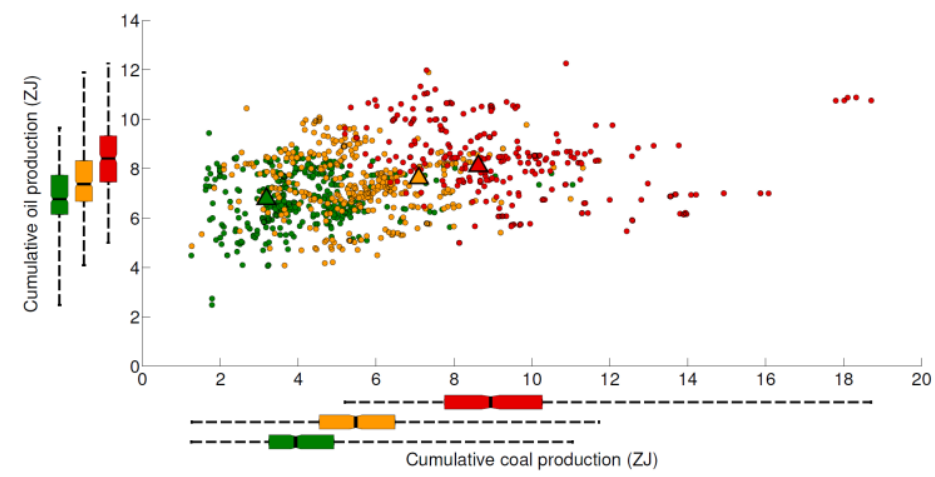

C

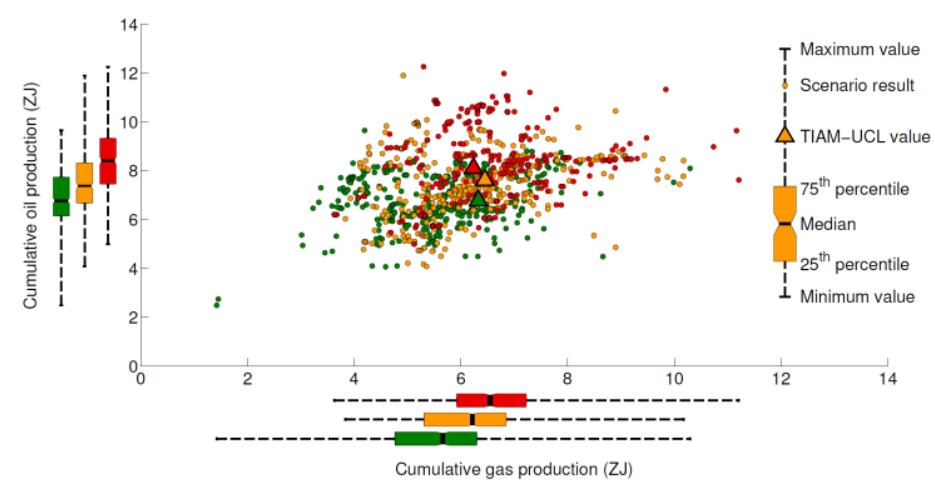

Figure 2: Cumulative production between 2010-2050 from a range of long-term energy system scenarios ${ }^{5}$ of coal and gas (a), coal and oil (b), and gas and oil (c). 


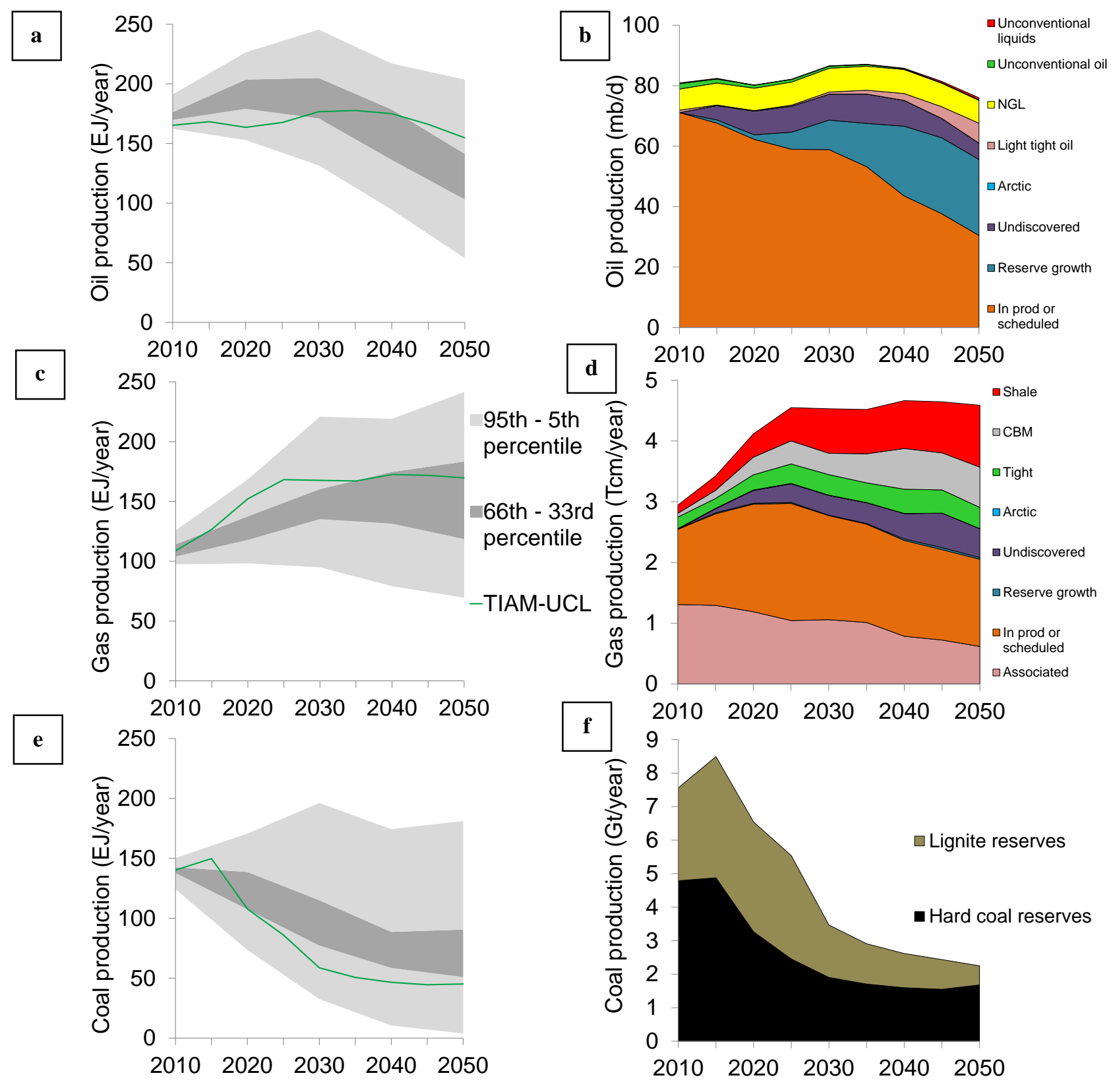

Figure 3: Oil, gas and coal production in the TIAM-UCL $2^{\circ} \mathrm{C}$ scenario (with CCS) and comparison with all other $2^{\circ} \mathrm{C}$ scenarios in the IPCC AR5 database ${ }^{5}$. 


\section{Methods}

\section{Fossil fuel definitions}

As mentioned in the main text, we define 'resources' to be the remaining ultimately recoverable resources (RURR). The RURR is the quantity of oil, gas or coal remaining that is recoverable over all time with both current and future technology, irrespective of current economic conditions. We define 'reserves' to be subset of resources that are: recoverable under current economic conditions, require current technology only, are in areas or fields that have been developed or have a set timetable to be developed, and have a specific probability of being produced. A 'McKelvey' box ${ }^{19}$ is often used to provide an overview of the relationship between different resource and reserve estimates ${ }^{20}$.

The best estimates of current oil and gas reserves in Table 1 were of the 'proved plus probable' or ' $2 \mathrm{P}$ ' quantities. Since $2 \mathrm{P}$ reserve estimates are rare for coal and none are in the public domain, the best estimates shown for coal were of the 'proved' or ' $1 \mathrm{P}$ ' reserves. Broadly speaking 1P estimates are more conservative, often corresponding to an estimate with a $90 \%$ probability of being exceeded, while $2 \mathrm{P}$ estimates are the median estimate of the reserves for a given field or region ${ }^{11}$.

Oil and gas can be further separated into 'conventional' and 'unconventional' reserves and resources. Again, there is no single definition of these terms, but here we define oil with density greater than water (often standardised as ' $10^{\circ} \mathrm{API}$ ') to be unconventional and all other quantities as conventional. We therefore categorise the light tight oil extracted from impermeable shale formations using hydraulic fracturing as conventional oil.

For gas, tight gas (gas trapped in relatively impermeable hard rock, limestone or 
sandstone), coal-bed methane (gas trapped in coal seams that is adsorbed in the solid matrix of the coal), and shale gas (gas trapped in fine grained shale) are considered as the three 'unconventional gases'; all other quantities are considered to be conventional.

Coal is distinguished by its energy density following the definitions used by the Federal Institute for Geosciences and Natural Resources (BGR) ${ }^{21}$. Hard coal has an energy density greater than $16.5 \mathrm{MJ} / \mathrm{kg}$; any quantities with energy density less than this are classified as lignite.

\section{Derivation of reserve and resource estimates}

The estimated oil and gas reserves and resources shown in Table 1 were derived in the following manner ${ }^{22}$.

We first identified the individual elements or categories of oil and gas that make up the global resource base. For oil these are: current conventional $2 \mathrm{P}$ reserves in fields that are in production or are scheduled to be developed, reserve growth, undiscovered oil, Arctic oil, light tight oil, natural gas liquids (NGL), natural bitumen, extra-heavy oil, and kerogen oil. The latter three of these are the unconventional oil categories.

Reserve growth is defined to be 'the commonly observed increase in recoverable resources in previously discovered fields through time ${ }^{, 23}$. Quantities in this category here include any contributions from: reserves in fields that have been discovered but are not scheduled to be developed ('fallow fields'), the new implementation of advanced production technologies such as enhanced oil recovery, changes in geological understanding, and changes in regional definitions.

There are eight categories of conventional and unconventional gas: current conventional $2 \mathrm{P}$ reserves that are in fields in production or are scheduled to be developed, reserve growth, 
undiscovered gas, Arctic gas, associated gas, tight gas, coal-bed methane, and shale gas. As noted above, the latter three of these are collectively referred to as unconventional gas.

We then selected the most robust data sources that provide estimates of the resource potential of each individual category within each country; these sources are set out in Extended Data Table 4. Taken together, differences between these sources provide a spread of discrete quantitative resource estimates for each category within each country. We also differentiated between the quantities of conventional oil that are NGL, and the quantities of natural gas that are associated with oil fields; these distinctions are important for modelling purposes but are rarely made in the literature.

For unconventional oil, we first generated a range of estimates for the in-place resources of natural bitumen, extra-heavy oil, and kerogen oil, and a range of potential recovery factors for different extraction technologies. We separately characterised the natural bitumen and kerogen oil resources that are extractable using mining technologies and those resources that are extractable using in situ technologies as the resource potential, costs, and energy requirements of these technologies are very different.

Continuous distributions were next constructed across these data ranges. Since there is no empirical basis for the choice of a suitable shape or form for such distributions, we used both the triangular and the beta distributions, chosen because they are flexible to be skewed positively and negatively, and because they allow identical distributions to be used across all of the ranges derived. With equal weighting for each distribution, we combined these into a single individual resource distribution for each category within each country.

We then estimated the production costs of each of the oil and gas resource categories. 
Taking account of the resource uncertainty, these were used to develop supply cost curves for each category of oil and gas within each country.

We finally used a Monte Carlo selection process to combine together these country-level supply cost curves. Regional supply cost curves were thus formed from aggregated supply cost curves for individual countries, and similarly supply cost curves formed for multiple categories of oil or gas within one or more countries. Data in Fig. 1 are the median values from these aggregate distributions with Extended Data Table 4 giving high $\left(95^{\text {th }}\right.$ percentile), median, and low $\left(5^{\text {th }}\right.$ percentile $)$ estimates for each category at the global level.

In most industry databases of oil and gas reserves (e.g. the database produced by the consultancy IHS CERA ${ }^{24,25}$ ), some of the quantities classified as reserves lie in fields that were discovered over ten years ago yet these fields have not been developed and there are no plans at present to do so. These are sometimes referred to as 'fallow fields'. For gas these quantities can also be called 'stranded gas', and they can be quite substantial; e.g. ${ }^{24}$ suggests $50 \%$ gas reserves outside of North America are in stranded fields. Strictly, oil and gas in such fields should not be classified as reserves (e.g. ${ }^{11}$ states that reserve quantities must have a 'reasonable timetable for development'). However, in this work, to ensure that the reserve estimates provided in Table 1 are not substantially different from the global totals provided by these industry databases, we follow their convention of classifying these quantities as reserves.

There are fewer independent estimates of reserves for coal and so we simply relied upon the estimates provided by the $\mathrm{BGR}^{21}$ for the reserve figures in Table 1 . The RURR of coal are more problematic to characterise, however. The 'resource' estimates provided by the BGR are not estimates of the quantities that can actually be extracted but are the in-place quantities; large 
portions of these are unlikely ever to be technically recoverable.

We therefore utilised the proved, probable and possible reserve estimates for hard coal and lignite provided by the World Energy Council (WEC) ${ }^{26}$ for a selection of countries. The sum of these three figures gives an estimate of the 'tonnage within the estimated additional amount in place that geological and engineering information indicates with reasonable certainty might be recovered in the future' (the definition provided by the WEC). Since the sum of these three figures takes account of technical recoverability, we consider that, while imperfect, they provide a better estimate of the ultimately recoverable resources of coal than either the (narrower) proved reserve or the (broader) in-place resource estimates.

There are a number of countries that are estimated by the BGR to hold large quantities of coal in place but for which no probable and possible reserve estimates are provided by the WEC. The ratio of the WEC resource estimate to the BGR in-place estimate in countries that have estimates provided by both sources can vary substantially, but the average ratio is $16 \%$ for hard coal and $31 \%$ for lignite. We therefore assumed this ratio to generate resource estimates for all countries for which only BGR in-place estimates are provided. The proved reserve estimates of coal are so large themselves that the resource estimates are less important than is the case for oil and gas resource estimates.

There are few other sources providing a comprehensive overview of fossil fuel availability. Further, these often do not provide their sources or methods used to generate estimates, define fully what categories or elements are included or excluded, or indicate sufficient conversion factors that would allow a like-with-like comparison. Some exceptions, however, are the IEA ${ }^{27,28}$, the IIASA Global Energy Assessment ${ }^{29}$, and the BGR ${ }^{21}$. Their 
estimates are shown together with our aggregated reserve and resource estimates in Extended Data Table 5.

A number of factors contribute to the large variation between these estimates. A key reason is that the definitions of 'reserves' and 'resources' differ between the sources, and so it is problematic to seek to compare them directly. For example, as noted above, the BGR, whose estimates are followed closely by the other sources, gives the total coal in place rather than an estimate of the resources that can be recovered, as in our study. Other reasons for the differences seen include:

- the exclusion or inclusion of certain categories of fossil fuels such as light tight oil, aquifer gas, and methane hydrates;

- whether proved (1P) or proved plus probable (2P) reserves are reported, and the methods used to generate the $1 \mathrm{P}$ reserve estimates;

- the potential inflation of reserve estimates for political reasons, and whether they should consequently be increased or reduced ${ }^{30}$;

- the inclusion of stranded gas volumes in gas reserve estimates;

- differences in the functional form used to estimate volumes of reserve growth (if reserve growth is included at all);

- the difficulty in estimating current recovery factors (the ratio of recoverable resources to total resources in place), and how these may increase in the future;

- differences between the methods used to estimate undiscovered oil and gas volumes; 
- the scarcity of reports providing reliable estimates of the potential resources of Arctic oil and gas, light tight oil, tight gas and coal bed methane, and the frequent consequent reliance upon expert judgement;

- variation in what unconventional oil production technologies, which vary considerably in their recovery factors, will be utilised in the future; and

- the chosen cut-off 'yield' (the volume of synthetic oil produced from a given weight of shale rock) for kerogen oil.

The estimates considered in our model are the result of careful and explicit consideration of all these issues, with our choices justified in the light of available knowledge. It can be seen in Extended Data Table 5, however, that our median figures are generally lower than the estimates provided by the other sources shown there. Therefore, although we consider our median resource estimates to be more robust than the figures used by these other sources, if in fact these other estimates were found to be closer to being correct, then the unburnable resources given in Extended Data Table 4 would also be larger. For example, if total gas resources are actually at the GEA high estimate, then the percentage that should be classified as unburnable before 2050 under the $2^{\circ} \mathrm{C}$ scenario would increase to $99 \%$ rather than our estimate of $75 \%$.

The cut-off date after which quantities that have not been produced should be considered 'unburnable' is also an important assumption. While there are no specific timeframes attached to the definition of reserves, quantities are usually required to be developed within, for example, a 'reasonable timeframe' ${ }^{11}$. It is doubtful whether any reserves not produced by 2050 would fulfil this criterion. We therefore take cumulative production of reserves between 2010 and 2050 as the reserve 'utilisation', and classify any quantities not used within this time as those that should be 
'unburnable' if a certain temperature rise is not to be exceeded. Similarly, if none, or only a minor proportion, of a certain non-reserve resource is produced prior to 2050 , then any current interest in developing it would be questionable. We thus also rely on 2050 as the cut-off date for classifying resources that should be considered as unburnable.

\section{Description and key assumptions in TIAM-UCL}

The TIMES Integrated Assessment Model in UCL ('TIAM-UCL') is a technology-rich, bottom-up, whole-system model that maximises social welfare under a number of imposed constraints. It models all primary energy sources (oil, gas, coal, nuclear, biomass, and renewables) from resource production through to their conversion, infrastructure requirements, and finally to sectoral end-use. An extended explanation of input assumptions, approaches, data sources can be found in ${ }^{13}$. The base year of TIAM-UCL is 2005, the model is run in full to 2100 , and thereafter the climate module is run to 2200 . Results are presented here only between 2010 and 2050 (and are reported in 5-year increments). All scenarios in this paper are run with the assumption of perfect foresight.

Resources and costs of all primary energy production are specified separately within 16 regions covering the world, and separately within the regions that contain members of OPEC; the names of these are presented in Extended Data Table 6. For clarity in the main text, we have aggregated some of these regions into 10 more-encompassing groups.

The climate module of TIAM-UCL is calibrated to the MAGICC model ${ }^{14}$. This module can be used to project the effects of greenhouse gas (GHG) emissions on: atmospheric concentrations of GHG, radiative forcing, and average global temperature rises. It can also be used to constrain the model to certain bounds on these variables. In this work, the climate 
module is used to restrict the temperature rise to certain levels (as explained below). For the calibration to MAGICC, values from the probability distributions of climate parameters in MAGICC were selected so that there is a $60 \%$ chance that the temperature rise will remain below any level reported. Any constraints imposed using the TIAM-UCL climate module also correspond to this probability.

The emissions profiles ${ }^{5}$ used in Fig. 2 were converted to temperature rises using MAGICC. To ensure consistency with TIAM-UCL, we use the $60^{\text {th }}$ percentile temperature trajectory from MAGICC and then group by the final temperature rise in 2100; there is therefore also a $60 \%$ chance that the temperature rise will be below the level indicated.

For each of the scenarios run in this paper using TIAM-UCL, a 'base case' is first formed that incorporates no GHG abatement policies. This base case uses the standard version of the model that relies upon minimising the discounted system cost. This is used to generate base prices for each commodity in the model. TIAM-UCL is then re-run using the elastic-demand version with the GHG abatement policies introduced. This version of the model maximises social welfare (the sum of consumer and producer surplus) and allows the energy-service demands to respond to changes in the endogenously determined prices resulting from these new constraints.

\section{Fossil fuel modelling in TIAM-UCL}

Oil and gas are both modelled in a similar manner in TIAM-UCL. The nine categories of conventional and unconventional oil and eight categories of conventional and unconventional gas identified above are all modelled separately. Coal production in TIAM-UCL is modelled more collectively, with only two categories, reserves and resources, for hard coal and lignite.

Natural bitumen and kerogen oil resources can be produced using either mining or in situ 
means, the technologies for which have different costs, efficiencies, and energy inputs. Although natural gas is predominantly used at present for the energy inputs to these unconventional resources, the model is free to choose any source of heat, electricity and hydrogen to allow greater flexibility. The costs of the auxiliary energy inputs required to extract and upgrade the native unconventional oils are determined endogenously by the model.

Each of the coal, gas and oil categories are modelled separately within the regions listed in Extended Data Table 6, with each resource category within each region split into three cost steps. As discussed above, the supply cost curves given in Fig. 1 comprise the data input to TIAM-UCL.

After processing, oil is next refined into products (gasoline, diesel, naphtha etc.) while processed gas and coal can be used directly. Fuel switching to and from all of the fossil fuels is possible. Trade of hard coal, crude oil, refined products, natural gas, both in pipelines and as liquefied natural gas, is allowed. Lignite cannot be traded between the regions.

Refined oil products can also be produced directly using Fischer-Tropsch processes with possible feedstocks of coal, gas, or biomass; these technologies can also be employed either with or without carbon capture and storage.

Regional coal, oil and gas prices are generated endogenously within the model. These incorporate the marginal cost of production, scarcity rents, rents arising from other imposed constraints, and transportation costs.

A new key aspect of TIAM-UCL is the imposition of asymmetric constraints on the rate of production of oil and gas given a certain resource availability; these are intended to represent 'depletion rate constraints'. In TIAM-UCL, these constraints are modelled through introducing 
maximum annual production growth and maximum 'decline rate' restrictions. These are imposed on each cost step of each category of both oil and gas in each region, and ensure that the production follows a more realistic profile over time.

Data for these constraints are available at the field level from the bottom-up economic and geological oil field production model ('BUEGO') ${ }^{31}$. BUEGO contains a data-rich representation of 7000 producing, undiscovered, and discovered but undeveloped oil fields. These data include each field's: $2 \mathrm{P}$ reserves, potential production capacity increases, water depth, capital and operating costs, and natural decline rate (the rate at which production would decline in the absence of any additional capital investment).

We used production-weighted averages (as of 2010) of the individual fields within each region to give average regional natural decline rates, which were imposed as maximum decline constraints in TIAM-UCL in the form of equal maximum annual reductions (on each cost step of each resource category within each region).

While data on gas natural decline rates are much more sparse, some are available at a regional level ${ }^{32}$, which can be compared with similar results for oil natural decline rates ${ }^{25}$. This comparison suggests that gas natural decline rates are on average 1\%/year greater than for oil, with similar distributions for location (onshore/offshore) and size. The constraints placed on the maximum annual reductions in natural gas production were thus assumed to be $1 \%$ higher than those derived for oil.

As identified in the main text, to understand the quantities of reserves of oil and gas that are unburnable, production only of reserve sources should be compared with reserve estimates, while cumulative production of all sources should be compared with the resource estimates. For 
coal, reserves are so much greater than cumulative production under any scenario that this distinction is not as important.

The base year of TIAM-UCL is 2005 while the base year of this study is 2010. Since reserves have grown, and oil and gas been discovered between these years, some quantities that were classified as reserve growth and undiscovered oil and gas in 2005 should be classified as reserves in 2010. Within each region, the cumulative production figures to which the reserve estimates in Table 1 are compared therefore contain production from the conventional $2 \mathrm{P}$ reserves in the 'fields in production or scheduled to be developed' category, as well as some portions of production from the 'reserve growth' and 'undiscovered' categories. In addition, since, for example, reserves of natural bitumen are included in the reserves figures of Canada and unconventional gas reserves are included in the reserves figures of the United States, production of some of the unconventional categories are also included in these cumulative production figures. To ensure consistency within each region, the maximum production potential over the modelling period from the categories included in the cumulative production figures is equal to the reserve estimates given in Table 1. Production by category and from reserves or nonreserve resources for both oil and gas for one of the modelled scenarios is presented in Fig 3.

\section{Overview of scenarios implemented}

A brief overview of the main assumptions within the four scenarios run as part of this work is provided in Extended Data Table 7. For the emissions mitigation scenarios (those that limit the temperature rise to $3^{\circ} \mathrm{C}$ and $2^{\circ} \mathrm{C}$ ), we assume that there are only relatively modest efforts to limit emissions in early periods as explained. The assumptions within the $2^{\circ} \mathrm{C}$ sensitivity scenarios used to construct Extended Data Fig. 1 are provided in Extended Data 
Table 2. 


\section{Extended Data legends}

Extended Data Table 1: Best estimates of remaining reserves and ultimately recoverable resources from 2010. FSU is the Former Soviet Union countries, CSA Central and South America (including Mexico), and ODA Other Developing Asia, 'Con' and 'Uncon' stand for Conventional and Unconventional respectively. Coal is specified in billion tonnes (Gt), gas in trillion cubic metres $(\mathrm{Tcm})$ and oil in billion barrels $(\mathrm{Gb})$.

Extended Data Table 2: Labels and description of the sensitivity scenarios modelled in this project.

Extended Data Table 3: Regional distribution of resources unburnable before 2050 in absolute terms and as a percentage of current resources under the $2^{\circ} \mathrm{C}$ scenario that allows CCS.

Extended Data Table 4: Principal data sources used to derive reserve and resource estimates and estimates at the global level for each category of production. High and low values are the aggregated $95^{\text {th }}$ and $5^{\text {th }}$ percentile estimates respectively.

Extended Data Table 5: Global aggregated oil, gas and coal reserve and resource estimates from a selection of data sources.

Extended Data Table 6: Regions included in TIAM-UCL and their aggregation to the regions given in the main text.

Extended Data Table 7: Labels and description of the four core scenarios modelled in this project.

Extended Data Figure 1: Cumulative fossil fuel production under a range of sensitivity scenarios run using TIAM-UCL. Scenario names and characteristics are given in Extended 
Data Table 2.

Extended Data Figure 2: The auxiliary energy inputs for natural bitumen production in Canada by in situ technologies in 2DS and the CO2 intensity of these. 


\begin{tabular}{|c|c|c|c|c|c|c|c|c|c|c|}
\hline \multirow[b]{2}{*}{$\begin{array}{l}\text { Country or } \\
\text { region }\end{array}$} & \multicolumn{3}{|c|}{ Oil (Gb) } & \multicolumn{3}{|c|}{ Gas (Tcm) } & \multicolumn{2}{|c|}{ Hard coal (Gt) } & \multicolumn{2}{|c|}{ Lignite (Gt) } \\
\hline & Res & $\begin{array}{l}\text { Con } \\
\text { RURR }\end{array}$ & $\begin{array}{l}\text { Uncon } \\
\text { RURR }\end{array}$ & Res & $\begin{array}{l}\text { Con } \\
\text { RURR }\end{array}$ & $\begin{array}{l}\text { Uncon } \\
\text { RURR }\end{array}$ & Res & RURR & Res & RURR \\
\hline Africa & 111 & 280 & 70 & 13 & 45 & 35 & 31 & 45 & 2 & 5 \\
\hline Canada & 53 & 60 & 640 & 1 & 5 & 25 & 4 & 35 & 2 & 40 \\
\hline China and India & 38 & 90 & 110 & 5 & 10 & 40 & 255 & 1,080 & 16 & 120 \\
\hline FSU & 152 & 370 & 360 & 61 & 95 & 30 & 123 & 580 & 94 & 490 \\
\hline CSA & 148 & 360 & 450 & 9 & 30 & 55 & 10 & 25 & 5 & 10 \\
\hline Europe & 25 & 110 & 30 & 6 & 25 & 20 & 17 & 70 & 66 & 160 \\
\hline Middle East & 689 & 1,050 & 10 & 76 & 105 & 20 & 2 & 10 & 2 & 5 \\
\hline OECD Pacific & 6 & 30 & 130 & 4 & 10 & 20 & 45 & 120 & 44 & 200 \\
\hline ODA & 23 & 75 & 5 & 9 & 25 & 15 & 15 & 40 & 14 & 155 \\
\hline United States & 50 & 190 & 650 & 8 & 25 & 40 & 226 & 560 & 31 & 335 \\
\hline Global & 1,294 & 2,615 & 2,455 & 192 & 375 & 300 & 728 & 2,565 & 276 & 1,520 \\
\hline
\end{tabular}

Extended Data Table 1: Best estimates of remaining reserves and ultimately recoverable resources from 2010. FSU is the Former Soviet Union countries, CSA Central and South America (including Mexico), and ODA Other Developing Asia, 'Con' and 'Uncon' stand for Conventional and Unconventional respectively. Coal is specified in billion tonnes (Gt), gas in trillion cubic metres $(\mathrm{Tcm})$ and oil in billion barrels $(\mathrm{Gb})$. 


\begin{tabular}{|c|c|}
\hline Sensitivity Name & Description \\
\hline 2DS_FFCHIGH & $\begin{array}{l}\text { Production costs of all fossil fuel technologies are } 50 \% \text { larger in } 2015 \text { and } \\
100 \% \text { larger in } 2020 \text { than in } 2 \mathrm{DS} \text {, with equal annual percentage changes } \\
\text { between these dates and remaining at this level for the model horizon }\end{array}$ \\
\hline 2DS_FFCLOW & $\begin{array}{l}\text { Production costs of all fossil fuel technologies are } 33 \% \text { lower in } 2015 \text { and } \\
50 \% \text { lower in } 2020 \text { than in 2DS, with equal annual percentage changes } \\
\text { between these dates and remaining at this level for the model horizon }\end{array}$ \\
\hline 2DS_BIOHIGH & $\begin{array}{l}\text { The maximum annual production of solid biomass and bio-crops in } 2050 \text { is } \\
\text { assumed to be } 350 \text { EJ. This is close to the highest level of production of } \\
\text { bio-energy in any of the scenarios from the AR5 scenario database }{ }^{5} \text { and is } \\
\text { around three times the equivalent figure in } 2 \mathrm{DS}(119 \mathrm{EJ}) \text {. }\end{array}$ \\
\hline 2DS_BIOLOW & $\begin{array}{l}\text { The maximum annual production of solid biomass and bio-crop in } 2050 \text { is } \\
\text { assumed to be } 38 \text { EJ. This is similar to the figure given in the central } \\
\text { scenario from }{ }^{33} \text { and is around a third of the equivalent figure in } 2 \mathrm{DS} \text { ( } 119 \\
\text { EJ). }\end{array}$ \\
\hline 2DS_OILHIGH & $\begin{array}{l}\text { Uses the high values of each category of oil in each region from the } \\
\text { aggregate resource distributions described in the methods section } \\
\text { (Extended Data Table 4) }\end{array}$ \\
\hline 2DS_OILLOW & $\begin{array}{l}\text { Uses the low values of each category of oil in each region (Extended Data } \\
\text { Table 4) }\end{array}$ \\
\hline 2DS_GASHIGH & $\begin{array}{l}\text { Uses the high values of each category of gas in each region (Extended Data } \\
\text { Table 4) }\end{array}$ \\
\hline 2DS_GASLOW & $\begin{array}{l}\text { Uses the low values of each category of gas in each region (Extended Data } \\
\text { Table 4) }\end{array}$ \\
\hline 2DS_DEMHIGH & $\begin{array}{l}\text { The major drivers of energy service demands in TIAM-UCL are growth in } \\
\text { GDP, population, and GDP/capita. Future regional growth in GDP and } \\
\text { population are therefore modified to the values given in Shared } \\
\text { Socioeconomic Pathway (SSP) number } 5^{34} \text { the SSP with the highest GDP } \\
\text { and GDP/capita growth by } 2050 \text { (a } 240 \% \text { increase in the global average; } \\
\text { cf. a } 120 \% \text { increase in } 2 D S \text { ). All other energy service demands (not relying } \\
\text { on GDP or population) are also modified commensurately. }\end{array}$ \\
\hline 2DS_DEMLOW & $\begin{array}{l}\text { Future regional growth in GDP and population are modified to the values } \\
\text { given in Shared Socioeconomic Pathway (SSP) number } 3: 34 \text { the SSP with } \\
\text { the lowest GDP and GDP/capita growth by } 2050 \text { (a } 50 \% \text { increase in the } \\
\text { global average). }\end{array}$ \\
\hline 2DS_NOBIOCCS & $\begin{array}{l}\text { No negative emissions technologies are permitted i.e. carbon capture and } \\
\text { storage (CCS) cannot be applied to any electrical or industrial process that } \\
\text { uses biomass or bio-energy as feedstock in any period. }\end{array}$ \\
\hline 2DS_NOCCS & $\begin{array}{l}\text { CCS is not permitted to be applied to any electrical or industrial process in } \\
\text { any period. }\end{array}$ \\
\hline
\end{tabular}

Extended Data Table 2: Labels and description of the sensitivity scenarios modelled in this

work 


\begin{tabular}{|c|c|c|c|c|c|c|c|c|c|c|c|c|}
\hline \multirow{2}{*}{$\begin{array}{l}\text { Country or } \\
\text { region }\end{array}$} & \multicolumn{2}{|c|}{ Conven oil } & \multicolumn{2}{|c|}{$\begin{array}{c}\text { Unconven } \\
\text { oil }\end{array}$} & \multicolumn{2}{|c|}{ Conven Gas } & \multicolumn{2}{|c|}{$\begin{array}{c}\text { Unconven } \\
\text { Gas }\end{array}$} & \multicolumn{2}{|c|}{ Hard Coal } & \multicolumn{2}{|c|}{ Lignite } \\
\hline & $\mathrm{Gb}$ & $\%$ & $\mathrm{~Gb}$ & $\%$ & $\mathrm{Tcm}$ & $\%$ & $\mathrm{Tcm}$ & $\%$ & Gt & $\%$ & Gt & $\%$ \\
\hline Africa & 141 & $50 \%$ & 70 & $100 \%$ & 28 & $61 \%$ & 35 & $100 \%$ & 42 & $94 \%$ & 2.8 & $56 \%$ \\
\hline Canada & 43 & $72 \%$ & 633 & $99 \%$ & 3.6 & $73 \%$ & 18 & $71 \%$ & 34 & $98 \%$ & 39 & $97 \%$ \\
\hline China and India & 54 & $60 \%$ & 110 & $100 \%$ & 8.0 & $80 \%$ & 35 & $88 \%$ & 1,003 & $93 \%$ & 106 & $88 \%$ \\
\hline FSU & 201 & $54 \%$ & 360 & $100 \%$ & 63 & $67 \%$ & 27 & $89 \%$ & 576 & $99 \%$ & 480 & $98 \%$ \\
\hline CSA & 198 & $55 \%$ & 447 & $99 \%$ & 23 & $76 \%$ & 51 & $92 \%$ & 21 & $85 \%$ & 6.3 & $63 \%$ \\
\hline Europe & 64 & $58 \%$ & 30 & $100 \%$ & 18 & $72 \%$ & 16 & $78 \%$ & 69 & $99 \%$ & 142 & $89 \%$ \\
\hline Middle East & 554 & $53 \%$ & 10 & $100 \%$ & 72 & $68 \%$ & 20 & $100 \%$ & 10 & $100 \%$ & 5.0 & $99 \%$ \\
\hline OECD Pacific & 23 & $77 \%$ & 130 & $100 \%$ & 9.0 & $90 \%$ & 15 & $74 \%$ & 116 & $97 \%$ & 198 & $99 \%$ \\
\hline ODA & 38 & $51 \%$ & 5.0 & $100 \%$ & 14 & $55 \%$ & 12 & $78 \%$ & 34 & $84 \%$ & 142 & $92 \%$ \\
\hline United States & 99 & $52 \%$ & 650 & $100 \%$ & 19 & $75 \%$ & 20 & $50 \%$ & 556 & $99 \%$ & 317 & $95 \%$ \\
\hline Global & 1,417 & $54 \%$ & 2,445 & $100 \%$ & 257 & $69 \%$ & 247 & $82 \%$ & 2,462 & $96 \%$ & 1,438 & $95 \%$ \\
\hline
\end{tabular}

Extended Data Table 3: Regional distribution of resources unburnable before 2050 in absolute terms and as a percentage of current resources under the $2^{\circ} \mathrm{C}$ scenario that allows CCS. 


\begin{tabular}{|c|c|c|c|c|}
\hline Category & $\begin{array}{l}\text { Data sources used to } \\
\text { provide country-level } \\
\text { estimates of resources }\end{array}$ & $\begin{array}{l}\text { Aggregated } \\
\text { high } \\
\text { estimate }\end{array}$ & $\begin{array}{l}\text { Aggregated } \\
\text { median } \\
\text { estimate }\end{array}$ & $\begin{array}{l}\text { Aggregated } \\
\text { low estimate }\end{array}$ \\
\hline Oil & & (in $\mathrm{Gb})$ & (in $\mathrm{Gb})$ & (in $G b)$ \\
\hline $\begin{array}{l}\text { Current conventional } 2 \mathrm{P} \\
\text { reserves in fields in production } \\
\text { or scheduled to be developed }\end{array}$ & $21,31,35,36$ & 950 & 820 & 620 \\
\hline Reserve growth & 37,38 & 1,200 & 850 & 610 \\
\hline Undiscovered oil & $\begin{array}{l}\text { Fact sheets since USGS } \\
\text { World Petroleum } \\
\text { Assessment }{ }^{39} \text { and } 35,40,41\end{array}$ & 580 & 300 & 180 \\
\hline Arctic oil & 42,43 & 80 & 65 & 40 \\
\hline Light tight oil & 10 & 470 & 300 & 150 \\
\hline Natural gas liquids (NGL) & 26 & & & \\
\hline & $\begin{array}{l}\text { Ancillary data associated } \\
\text { with } 39\end{array}$ & 380 & 280 & 170 \\
\hline Natural bitumen & $\begin{array}{l}\text { Oil in place estimates } \\
17,26 \\
\text { Extraction technologies } \\
17,44,45\end{array}$ & $\begin{array}{c}\text { Mined RURR } \\
130 \\
\text { In Situ RURR } \\
1290\end{array}$ & $\begin{array}{c}\text { Mined RURR } \\
100 \\
\text { In Situ RURR } \\
840\end{array}$ & $\begin{array}{c}\text { Mined RURR } \\
70 \\
\text { In Situ RURR } \\
520\end{array}$ \\
\hline Extra-heavy oil & $\begin{array}{l}\text { Oil in place estimates } \\
46,47 \\
\text { Extraction technologies } \\
46 \text { and refs for bitumen }\end{array}$ & 750 & 440 & 230 \\
\hline Kerogen oil & $\begin{array}{l}\text { Oil in place estimates } \\
48,49 \\
\text { Extraction technologies } \\
50\end{array}$ & $\begin{array}{c}\text { Mined RURR } \\
740 \\
\text { In Situ RURR } \\
1,080\end{array}$ & $\begin{array}{c}\text { Mined RURR } \\
485 \\
\text { In Situ RURR } \\
590\end{array}$ & $\begin{array}{c}\text { Mined RURR } \\
270 \\
\text { In Situ RURR } \\
190\end{array}$ \\
\hline Total & & 7,650 & 5,070 & 3,050 \\
\hline Gas & & (in tcm) & (in tcm) & (in tcm) \\
\hline $\begin{array}{l}\text { Current conventional } 2 \mathrm{P} \\
\text { reserves in fields in production } \\
\text { or scheduled to be developed }\end{array}$ & 35,51 & 140 & 130 & 110 \\
\hline Reserve growth & $24,37,38$ & 125 & 90 & 60 \\
\hline Undiscovered gas & $\begin{array}{l}\text { Fact sheets since USGS } \\
\text { World Petroleum } \\
\text { Assessment }{ }^{39} \text { and }{ }^{35,41}\end{array}$ & 180 & 120 & 80 \\
\hline Arctic gas & 42,43 & 40 & 35 & 25 \\
\hline Tight gas & 20 & 60 & 60 & 60 \\
\hline Coal-bed methane & 20 & 45 & 40 & 20 \\
\hline Shale gas & 20 & 310 & 200 & 120 \\
\hline Associated gas & $36,37,52$ & \multicolumn{3}{|c|}{ Included in the above } \\
\hline Total & & 900 & 675 & 475 \\
\hline
\end{tabular}


Extended Data Table 4: Principal data sources used to derive reserve and resource estimates and estimates at the global level for each category of production. High and low values are the aggregated $95^{\text {th }}$ and $5^{\text {th }}$ percentile estimates respectively.

\begin{tabular}{|c|c|c|c|c|c|c|}
\hline \multirow[b]{2}{*}{ Organisation } & \multicolumn{2}{|c|}{ Oil (Gb) } & \multicolumn{2}{|c|}{ Gas (Tcm) } & \multicolumn{2}{|c|}{ Coal (Gt) } \\
\hline & Reserves & Resources & Reserves & Resources & Reserves & Resources \\
\hline BGR & 1,600 & 4,750 & 195 & 825 & 1,050 & 23,500 \\
\hline IEA & 1,700 & 5,950 & 190 & 810 & 1,000 & 21,000 \\
\hline GEA & $\begin{array}{l}1,500- \\
2,300\end{array}$ & $\begin{array}{c}4,200- \\
6,000\end{array}$ & $670-2,000$ & $\begin{array}{l}2,000- \\
12,500\end{array}$ & $850-1,000$ & $\begin{array}{c}14,000- \\
20,000\end{array}$ \\
\hline $\begin{array}{l}\text { This study's } \\
\text { median figures }\end{array}$ & 1,300 & 5,070 & 190 & 680 & 1,000 & 4,085 \\
\hline
\end{tabular}

Extended Data Table 5: Global aggregated oil, gas and coal reserve and resource estimates from a selection of data sources. 


\begin{tabular}{ll}
\hline Region & Aggregated region in main text \\
\hline Non-OPEC Africa & Africa \\
OPEC Africa & Africa \\
Australia & OECD Pacific \\
Canada & Canada \\
Non-OPEC Central and South America & Central and South America (CSA) \\
OPEC Central and South America & Central and South America (CSA) \\
China & China and India \\
Eastern Europe & Europe \\
Former Soviet Union & Former Soviet Union (FSU) \\
India & China and India \\
Japan & OECD Pacific \\
Non-OPEC Middle & Middle East \\
OPEC Middle East & Middle East \\
Mexico & Central and South America (CSA) \\
Other Developing Asia & Other Developing Asia (ODA) \\
South Korea & OECD Pacific \\
United Kingdom & Europe \\
United States & United States \\
Western Europe & Europe \\
\hline
\end{tabular}

Extended Data Table 6: Regions included in TIAM-UCL and their aggregation to the regions given in the main text 


\begin{tabular}{|c|c|}
\hline Scenario Name & Description \\
\hline \multirow[t]{3}{*}{ 5DS } & $\begin{array}{l}\text { The model is constrained to keep the average global surface temperature } \\
\text { rise to less than } 5^{\circ} \mathrm{C} \text { in all years to } 2200 \text {. }\end{array}$ \\
\hline & $\begin{array}{l}\text { No other emissions constraints are imposed, and since allowed emissions } \\
\text { under this scenario are so high (i.e. the constraint is very lax), no real } \\
\text { emissions mitigation is required. }\end{array}$ \\
\hline & $\begin{array}{l}\text { These constraints result in } 2050 \mathrm{GHG} \text { emissions of } 71 \mathrm{Gt} \mathrm{CO}_{2} \text {-eq (up from } \\
\text { around } 48 \mathrm{Gt} \mathrm{CO}_{2} \text {-eq in 2010). }\end{array}$ \\
\hline \multirow[t]{4}{*}{$3 D S$} & $\begin{array}{l}\text { From } 2005 \text { to } 2010 \text {, the model is fixed to the solution given in the } 5^{\circ} \mathrm{C} \\
\text { temperature i.e. we assume that no emissions reductions are required. }\end{array}$ \\
\hline & $\begin{array}{l}\text { From 2010-2015, it is assumed that the model must be on track to achieve } \\
\text { the emissions reduction pledges set out in the Copenhagen Accord }{ }^{1} \text {, but } \\
\text { no other emissions reductions are required. }\end{array}$ \\
\hline & $\begin{array}{l}\text { From } 2015 \text { onwards the model must meet the Copenhagen Accord } \\
\text { emissions reductions in } 2020 \text {, and emissions must be such as to keep the } \\
\text { average global surface temperature rise below } 3^{\circ} \mathrm{C} \text { in all years to } 2200 \text {. }\end{array}$ \\
\hline & These constraints result in $2050 \mathrm{GHG}$ emissions of $54 \mathrm{Gt} \mathrm{CO}_{2}$-eq \\
\hline \multirow[t]{3}{*}{ 2DS } & $\begin{array}{l}\text { The constraints between } 2005 \text { and } 2015 \text { in this scenario are identical to } \\
\text { the 3DS. }\end{array}$ \\
\hline & $\begin{array}{l}\text { From } 2015 \text { onwards the model must meet the Copenhagen Accord } \\
\text { emissions reductions in } 2020 \text {, and emissions must be such as to keep the } \\
\text { average global surface temperature rise below } 2^{\circ} \mathrm{C} \text { in all years to } 2200 \text {. }\end{array}$ \\
\hline & These constraints result in $2050 \mathrm{GHG}$ emissions of $21 \mathrm{Gt} \mathrm{CO}_{2}$-eq \\
\hline \multirow[t]{2}{*}{ 2DS-noCCS } & Emissions reduction requirements are identical to 2DS. \\
\hline & $\begin{array}{l}\text { Carbon capture and storage (CCS) is not permitted to be applied to any } \\
\text { electricity or industrial process in any period. }\end{array}$ \\
\hline
\end{tabular}

Extended Data Table 7: Labels and description of the four core scenarios modelled in this work 


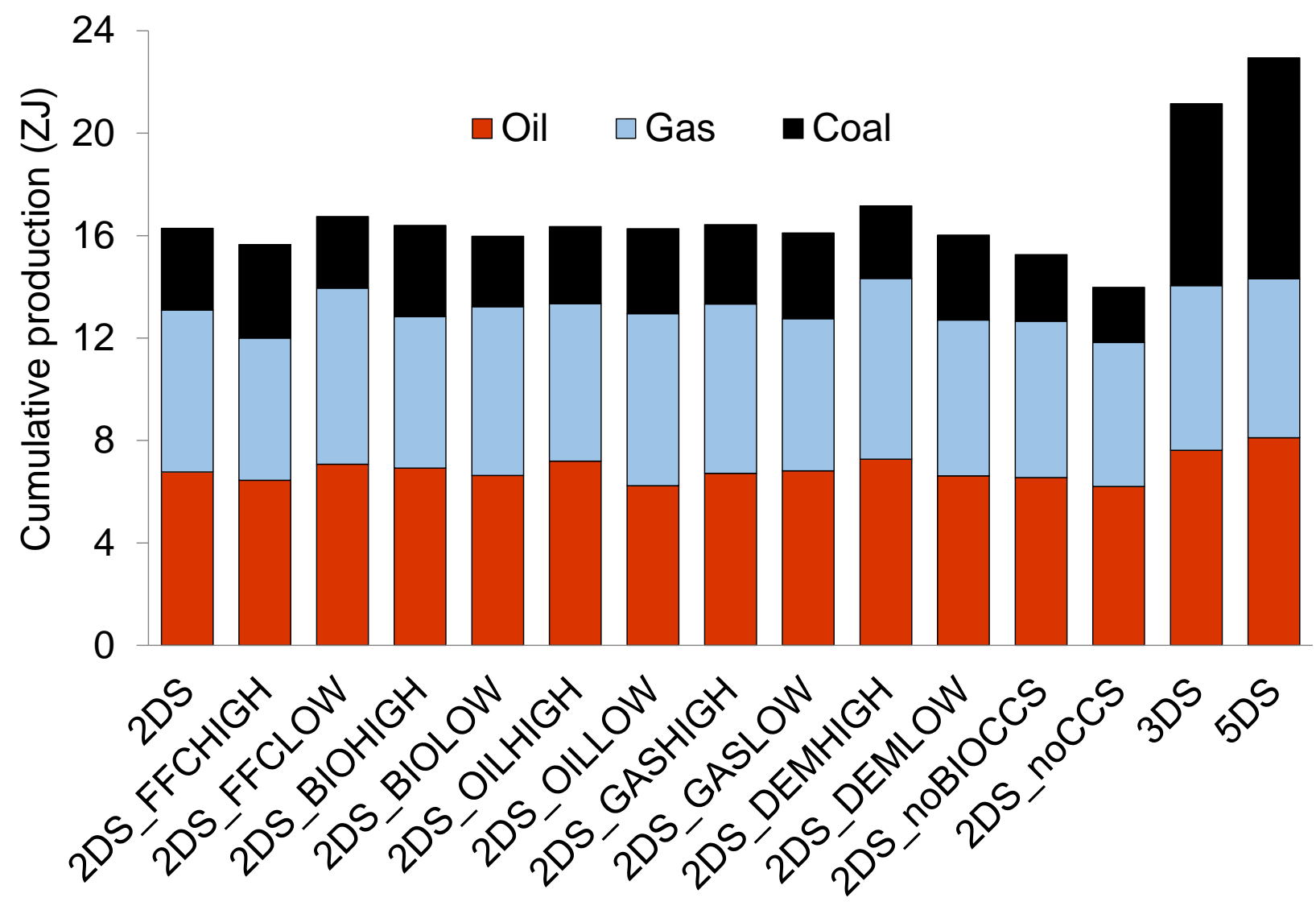

Extended Data Figure 1: Cumulative fossil fuel production under a range of sensitivity scenarios run using TIAM-UCL. Scenario names and characteristics are given in Extended Data Table 2. 


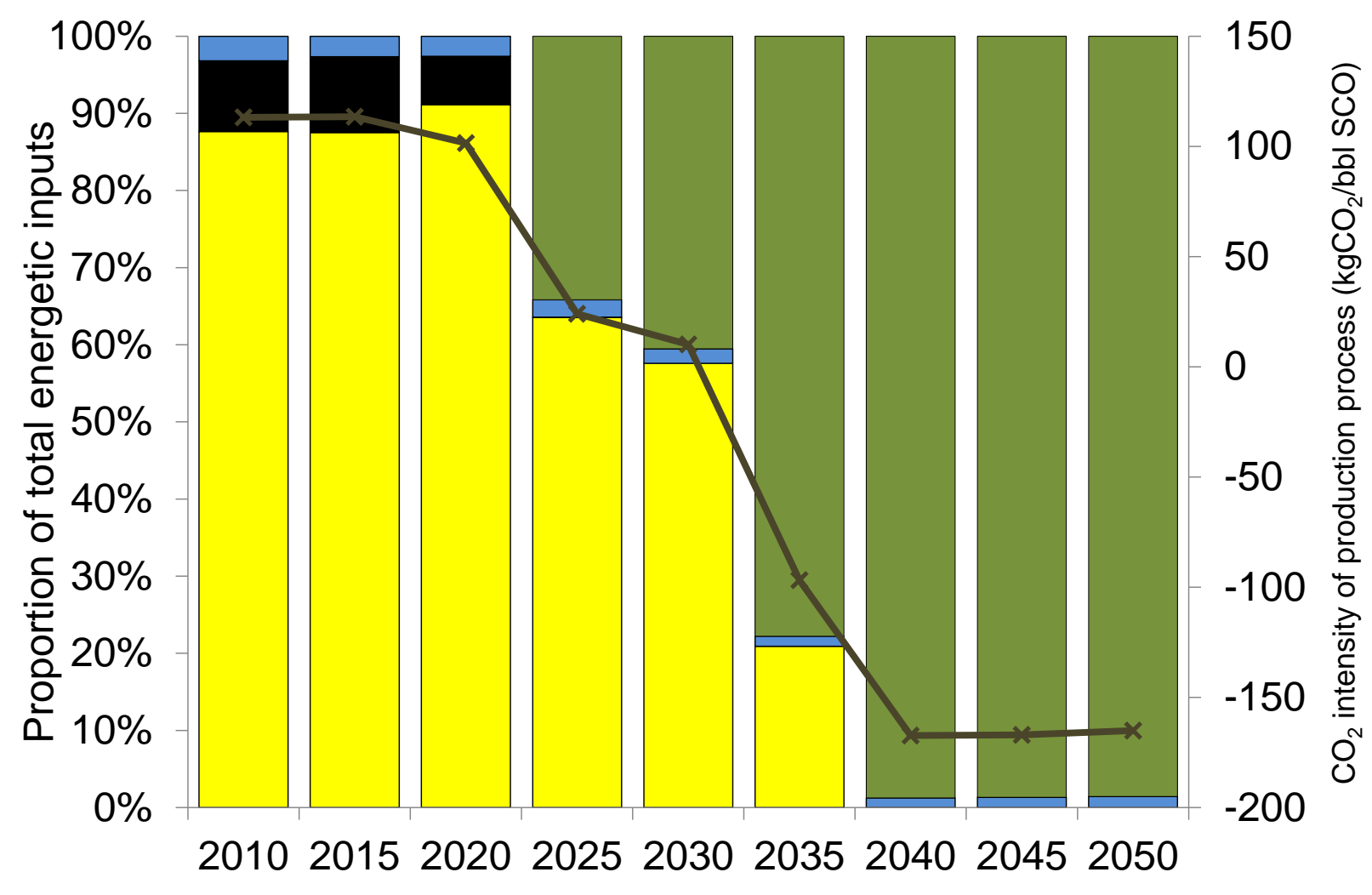

$\square$ Gas $\square$ Coal $\square$ Renewables \& nuclear $\square$ Biomass $\square$ Coke $*$ CO2 intensity

Extended Dat a Figure 2: The auxiliary energy inputs for natural bitumen production in

Canada by in situ technologies in 2DS and the $\mathrm{CO}_{2}$ intensity of these. 